\title{
Humus de lombriz como alternativa para mejorar la fertilidad de los suelos arenosos de huertas
} agroecológicas

*Colonese, María Del C. ${ }^{1}$; Bernardi, María J. ${ }^{1}$; Cotorruelo, Joaquin ${ }^{1}$ Y Saucedo, Raymunda ${ }^{2}$

${ }^{1}$ INTA. AER Goya, J. J. Rolòn 750, 03777-432285, *E-mail:colonese.maria@ inta.gob.ar

${ }^{2}$ Promotora de Prohuerta, Ruta Nacional $\mathrm{N}^{\circ} 12 \mathrm{~km} 758$, tercera sección paraje Buena Vista Goya Corrientes, 03777-15539735

Introducción: En la Lombricultura se utilizan las lombrices para acelerar la transformación de desechos orgánicos con la finalidad de generar productos naturales tales como el abono de lombriz, material rico en microorganismos; también se puede aprovechar la carne de la lombriz de altos contenidos de proteína, vitaminas y aminoácidos.Por todo lo mencionado anteriormente, en cuanto a las múltiples ventajas o beneficios que posee el abono de lombriz es que nos incentivó a comenzar esta experiencia en el paraje Buena Vista, como herramienta para mejorar las propiedades del suelo que caracteriza a esa zona, el mismo tiene alto porcentaje de arena, pobres en materia orgánica y nutrientes. El objetivo de esta experiencia es superar el inconveniente del suelo sin utilizar fertilizantes químicos remplazándolo por abono orgánico producto de la lombricultura, obteniendo alimentos sanos de la huerta diversificando y cuidando el medio ambiente.

Materiales y métodos: La práctica de la lombricultura fue adaptada a las condiciones y materiales con los que contaba la familia productora. En base al manejo que le daba la productora, decidimos tomar muestras en dos situaciones diferentes, a las que llamamos: Tratamiento 1: suelo + tierra de monte $(6 \mathrm{~kg})$; es el que elegimos de testigo, es un tablón de 3 metros de largo por 1 metro de ancho. Tratamiento 2 : suelo + tierra de monte $(6 \mathrm{~kg})+$ lombricompuesto $(6 \mathrm{~kg})$, consta de 6 tablones de 3 metros de largo por 1 metro de ancho. Se realizaron muestreosal azar y posterior análisis de los suelos del tratamiento 1 y 2 , también del producto que se obtiene del lombricompuesto. En los tres casos se determinó en laboratorio: pH; Fosforo asimilable (P); Bases de intercambio: Calcio (Ca), Magnesio $(\mathrm{Mg})$, Potasio $(\mathrm{K})$ y Sodio (Na); Materia Orgánica (MO), Carbono Orgánico (CO), Nitrógeno Total (NT) y Conductividad Eléctrica (CE).

Resultados:El análisis de suelo del tratamiento 1 (Ver tabla $\mathrm{N}^{\circ} 1$ ) expresa las características típicas de los suelos arenosos, pobre en nutrientes y principalmente su bajo contenido en materia orgánica, con excepción del fosforo.Los datos del tratamiento 2, refleja la importancia de la incorporación del lombricompuesto como fertilizante natural, los valores son mayores al tratamiento 1 . También vale aclarar que los niveles de fósforo y nitrógeno son muy altos, porque en este caso tendríamos que ajustar mejor la dosis de lombricompuesto en cada tablón, y mejorar la eficiencia en el uso del mismo. $\mathrm{El} \mathrm{pH}$ y la conductividad de ambos tratamientos ronda en valores normales e ideales para el desarrollo de los cultivos que producen.

Los resultados del producto que se obtiene de la lombricultura (Ver tabla $\mathrm{N}^{\circ} 1$ ) es un reservorio de un alto contenido en nutrientes (Calcio, Magnesio, Fósforo, Nitrógeno y Potasio). En el caso del sodio este es alto, pero en relación con los otros cationes no alcanza a ser un problema.El lombricompuesto analizado posee un contenido en materia orgánica alto, el mismo al incorporarse al suelo arenoso es muy beneficioso, ya que mejora sus condiciones, sobre todo en la formación de agregados más estables y esto hace aumentar la porosidad y la retención de humedad. En los casos de altas precipitaciones que se registraron en los últimos años y vientos muy fuertes, este aspecto se vuelve de importancia ya que disminuimos los problemas por erosión hídrica y eólica, comunes en este tipo de suelo.

Conclusiones:La lombricultura es una herramienta de suma importancia en los suelos arenosos pobres en nutrientes, ya que mejora las condiciones de fertilidad del mismo, con esto elaboramos un producto, de fácil manejo, ecológicamente constituye un elemento para la producción orgánica y un abono eficiente y rentable para la producción, sobre todo de pequeños productores. Con esta experiencia podemos concluir que la dosis de lombricompuesto debería ser más baja, $900 \mathrm{~g}$ a $1 \mathrm{~kg}$ de lombricompuesto por $\mathrm{m}^{2}$, porque se ve un aumento en el contenido de fósforo en el tratamiento 2, el cual podría ser, a largo plazo, un problema en cuanto a la disponibilidad de otros nutrientes y mejorar así la eficiencia en su uso.

Tabla No1: Análisis de suelo y del lombricompuesto. Laboratorio de Suelos, Aguas de Santa Lucía, Corrientes

\begin{tabular}{|c|c|c|c|c|c|c|c|c|c|}
\hline \multirow[t]{2}{*}{ Identificación } & pH & CE & MO & $\mathrm{N}-\mathrm{NO}_{3}$ & $\mathrm{Ca}$ & Mg & $\mathbf{K}$ & $\mathbf{N a}$ & \multirow{2}{*}{$\begin{array}{c}\mathbf{P} \\
\mathbf{p p m}\end{array}$} \\
\hline & & Mmho/cm & $\%$ & ppm & \multicolumn{4}{|c|}{ cmolc/kg } & \\
\hline Tratamiento 1 & 7,2 & 0,06 & 0,45 & 1,35 & 3,10 & 1,06 & 0,10 & 0,12 & 67,2 \\
\hline Tratamiento 2 & 6,9 & $\mathbf{0 , 2 3}$ & 1,2 & 18,7 & 3,60 & 2,40 & $\mathbf{0 , 3 1}$ & 0,19 & 311,3 \\
\hline $\begin{array}{l}\text { Humus de } \\
\text { Lombriz }\end{array}$ & 5,6 & 3,18 & 6,2 & 506,3 & 9,5 & 6,3 & 3,12 & 0,69 & 637,5 \\
\hline
\end{tabular}

Agradecimientos: Se destaca el trabajo que realiza la familia, con el acompañamiento de los técnicos de INTA, por transmitir a los vecinos su experiencia personal con la práctica de la lombricultura, como así también a las escuelas cercanas del paraje. 